DOI: 10.20472/IAC.2019.047.020

\author{
TOSHIYUKI SAKABE \\ Hokkaido University of Science, Japan
}

KATE SATO

Hokkaido University of Science, Japan

\title{
ACTION RESEARCH ON ASYNCHRONOUS INTER-CULTURAL COMMUNICATION VIDEO EXCHANGES
}

\begin{abstract}
:
Japanese university students studying the sciences often lack opportunities to communicate globally with other students in English. In order to offer opportunities to such students an asynchronous inter-cultural communication video exchange (ICVE) was included as classroom activities as a part of the syllabus the presenters' classroom. The aim was to open the way for students to deepen inter-cultural understanding while practicing their English language skills. Students were put into groups, and during the semester each group recorded 4 videos. The videos were exchanged with international students studying at a university in Finland. At the end of the semester in the first year of the ICVE, questionnaire was conducted to uncover the students' perspectives about the ICVE. The results showed about $70 \%$ of students felt that 4 videos during one 15 week semester was too many. Nevertheless, all of the students said they would you recommend the ICVE to a friend. The results also indicated: more time is needed to practice before shooting the video, the students should/did enjoy/ed themselves, and group members should have been changed for each video recording. From the results the following year's ICVE was planned resulting two main changes: the number of videos being reduced from four to three, and, the members of each group being different for each video recording. At the end of the semester a similar questionnaire was conducted. This presentation shares the results from the second year of the ICVE and discusses how the ICVE can be conducted concurrent with other activities in the syllabus. Also a comparison of the results of the two years of questionnaires feedback will also be highlighted. This presentation will help others who are considering establishing their own inter-cultural global communication exchange activity through video exchanges in their classrooms.
\end{abstract}

\section{Keywords:}

English Education

English Teaching

Inter-Cultural Communication

Video Exchange

JEL Classification: 129 